LONGTERM NATURAL HISTORY OF RADIOFREQUENCY INTRAVASCULAR ULTRASOUND IDENTIFIED

\title{
CORONARY PLAQUES
}

P A Calvert, ${ }^{1}$ D R Obaid, ${ }^{1}$ M O'Sullivan, ${ }^{2}$ L M Shapiro, ${ }^{2}$ D C McNab, ${ }^{2}$ C G Densem, ${ }^{2}$ S P Hoole, $^{2}$ P M Schofield, ${ }^{2}$ D M Braganza, ${ }^{2}$ S C Clarke, ${ }^{2}$ N E West, ${ }^{2}$ M R Bennett ${ }^{1}$ ${ }^{1}$ University of Cambridge; ${ }^{2}$ Papworth Hospital NHS Foundation Trust

doi:10.1136/heartjnl-2013-304019.53

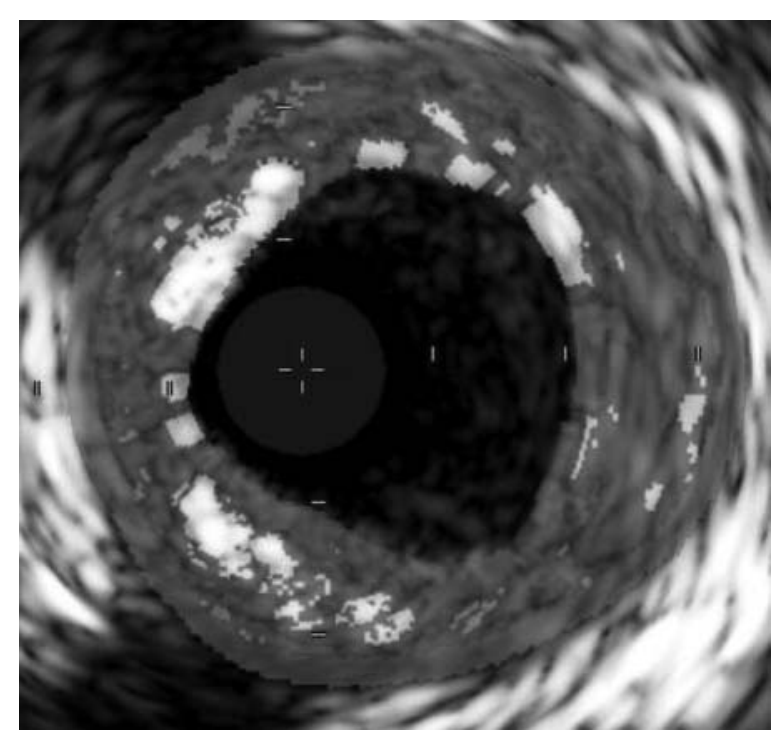

Figure 1 VH-IVUS thin-capped fibroatheroma (VHTCFA). 


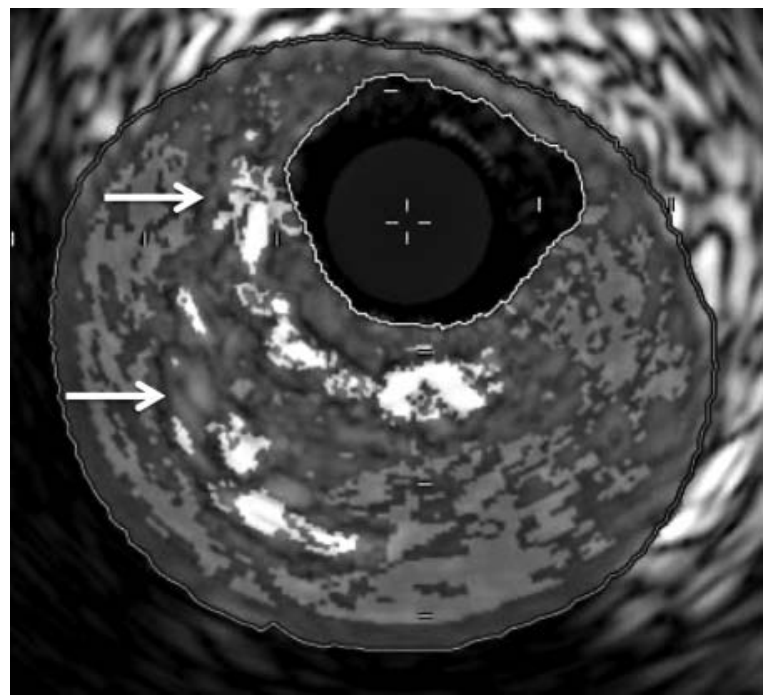

Figure 2 VH-IVUS thick-capped fibroatheroma (VHThCFA).

Introduction Prior studies have shown that virtual-histology intravascular ultrasound (VH-IVUS) identified thin-capped fibroatheroma (VHTCFA) (figure 1) and plaque burden (PB) $>70 \%$ are associated with major adverse cardiovascular events (MACE). This study examined non-culprit lesion features that predict MACE in long-term follow up and culprit lesion features responsible for myocardial infarction (MI).

Methods 170 patients with stable angina $(n=100)$ or MI $(n=70)$ underwent three-vessel VH-IVUS prior to percutaneous coronary intervention (PCI). Patients were followed for MACE which consisted of death, MI, cerebrovascular event, hospitalisation with unstable angina or unplanned revascularisation. Non-culprit lesion features were tested for association with future MACE, and culprit lesion features were assessed for initial presentation with MI, using univariate and multivariate analysis.

Results $30372 \mathrm{~mm}$ of VH-IVUS were analysed and 1096 plaques classified. 45 MACE occurred in 30 patients over a median follow up of 1115 (968-1537) days. These included 3 deaths, 6 MIs, 3 cerebrovascular events, 15 hospitalisations due to unstable angina, 3 unplanned coronary bypass operations and 15 unplanned PCI.

By univariate analysis, non-culprit VHTCFA ( $\mathrm{HR}=7.37, \mathrm{p}=0.014)$, $\mathrm{MLA}<4 \mathrm{~mm}^{2} \quad(\mathrm{HR}=3.61, \mathrm{p}=0.028)$ and $\mathrm{PB}>70 \% \quad(\mathrm{HR}=7.77$, $\mathrm{p}<0.001)$ were associated with future non-restenotic MACE on longterm follow up (table 1). By multivariate analysis $\mathrm{PB}>70 \%$ $(\mathrm{HR}=7.77, \mathrm{p}<0.001)$ remained independently associated with MACE.

On univariate analysis, multiple culprit lesion features were associated with initial presentation with MI (table 2), including total and calcified VHTCFA, remodelling index, PB>70\%, MLA $<4 \mathrm{~mm}^{2}$, plaque rupture and thrombus. By multivariate analysis, $\mathrm{PB}>70 \% \quad(\mathrm{OR} \quad(\mathrm{OR})=6.32, \mathrm{p}<0.001)$, thrombus $(\mathrm{OR}=9.03$, $\mathrm{p}<0.001)$ and $\mathrm{MLA}<4 \mathrm{~mm} 2(\mathrm{OR}=3.01, \mathrm{p}=0.02)$ were independently associated with MI.

Interestingly, culprit lesion calcified VHTCFA were associated with initial MI $(O R=2.59$ (1.61-4.16), $p<0.001)$, whereas noncalcified VHTCFA were more likely to be associated with future MACE HR=4.01 (0.87-18.68), $p=0.077$.

Conclusion Despite the dynamic nature of coronary plaques, nonculprit VHTCFA, MLA $<4 \mathrm{~mm}^{2}$ and $\mathrm{PB}>70 \%$ were associated with future $\mathrm{MACE}$ on long-term follow up, with $\mathrm{PB}>70 \%$ being independently associated. These same features in culprit lesions (amongst others) were associated with MI presentation, emphasising their biological importance. Interestingly, non-calcified VHTCFA are more likely to be associated with future MACE, whereas it is the calcified variant that is associated with MI

Table 1

\begin{tabular}{|c|c|c|c|c|}
\hline Plaque characteristics & Univariate analysis $\mathrm{HR}(95 \% \mathrm{CI})$ & Univariate analysis $\mathrm{p}$ value & Multivariate analysis HR (95\% CI) & Multivariate analysis $p$ value \\
\hline VHThCFA & $1.17(0.23$ to 6.24$)$ & 0.86 & & \\
\hline Total VHTFCA & $6.37(1.45$ to 27.94$)$ & 0.014 & $2.18(0.41$ to 11.71$)$ & 0.36 \\
\hline Non-calcified VHTCFA & 4.01 (0.87 to 18.68$)$ & 0.077 & $2.91(0.57$ to 15.00$)$ & 0.20 \\
\hline Calcified VHTCFA & $1.51(0.40$ to 5.75$)$ & 0.55 & & \\
\hline Remodelling index & $26.82(0.36$ to 1975$)$ & 0.13 & & \\
\hline $\mathrm{MLA}<4 \mathrm{~mm}^{2}$ & $3.61(1.15$ to 11.32$)$ & 0.028 & $1.23(0.24$ to 6.22$)$ & 0.80 \\
\hline Plaque burden $>70 \%$ & 7.77 (2.06 to 29.28$)$ & 0.002 & 7.77 (2.06 to 29.28$)$ & 0.002 \\
\hline Plaque volume $\left(\mathrm{mm}^{3}\right)$ & $1.00(1.00$ to 1.00$)$ & 0.34 & & \\
\hline Necrotic core volume $\left(\mathrm{mm}^{3}\right)$ & $1.00(0.99$ to 1.01$)$ & 0.57 & & \\
\hline NC percentage & $1.01(0.93$ to 1.10$)$ & 0.79 & & \\
\hline
\end{tabular}

Table 2

\begin{tabular}{|c|c|c|c|c|}
\hline Plaque characteristics & Univariate analysis OR (95\% CI) & Univariate analysis $\mathrm{p}$ value & Multivariate analysis $\mathrm{OR}(95 \% \mathrm{Cl})$ & Multivariate analysis $\mathrm{p}$ value \\
\hline VHThCFA & $0.84(0.44$ to 1.60$)$ & 0.59 & & \\
\hline Total VHTFCA & 3.05 (1.78 to 5.23 ) & $<0.001$ & & \\
\hline Non-calcified VHTCFA & $1.18(0.66$ to 2.10$)$ & 0.58 & & \\
\hline Calcified VHTCFA & 2.59 (1.61 to 4.16$)$ & $<0.001$ & & \\
\hline Remodelling index & 28.05 (5.53 to 142.25$)$ & $<0.001$ & & \\
\hline $\mathrm{MLA}<4 \mathrm{~mm} 2$ & $8.86(5.18$ to 15.14$)$ & $<0.001$ & 3.01 (1.52 to 5.96$)$ & 0.002 \\
\hline Plaque burden $>70 \%$ & 15.41 (8.80 to 27.01$)$ & $<0.001$ & $6.32(3.23$ to 12.37$)$ & $<0.001$ \\
\hline Plaque volume $\left(\mathrm{mm}^{3}\right)$ & $1.004(1.002$ to 1.005$)$ & $<0.001$ & & \\
\hline Thrombus & 20.29 (5.58 to 73.76$)$ & $<0.001$ & 9.03 (1.60 to 50.98$)$ & 0.013 \\
\hline Ruptured plaque & 6.77 (2.09 to 21.92 ) & 0.001 & & \\
\hline
\end{tabular}


presentation. This may represent a phenotypic transformation in the VHTCFA from non-calcified to calcified which could reflect multiple healed plaque rupture events (figure 2). This theory requires further investigation.

Table 1 Non-culprit lesion features associated with future MACE

VHThCFA (VH-IVUS thick-capped fibroatheroma), VHTCFA (VH-IVUS thin-capped fibroatheroma), MLA (minimum luminal area), NC (necrotic core), $\mathrm{HR}, \mathrm{CI}$

Table 2 Culprit lesion features associated with MI presentation

OR

Note that this fibroatheroma has two distinct layers (arrows) of necrotic core (red) and dense calcium (white), perhaps representing two temporally distinct plaque rupture events that have now healed. 